\title{
Reducing the anchoring bias in multiple question CV surveys
}

\author{
Victor Champonnois $^{\mathrm{a}}$, Olivier Chanel ${ }^{\mathrm{a}, *}$, Khaled Makhloufi ${ }^{\mathrm{b}}$ \\ ${ }^{a}$ Aix-Marseille Univ., CNRS, EHESS, Centrale Marseille and AMSE, 5 boulevard Maurice Bourdet CS50498 13205 Marseille cedex 01, France \\ ${ }^{\mathrm{b}}$ Aix-Marseille Univ., INSERM-IRD-UMR 912 (SESSTIM), Faculty of Medicine - Timone, 27 Bd Jean Moulin, 13385 Marseille cedex 5, France
}

\begin{abstract}
A B S T R A C T
The elicitation format is a crucial aspect of Contingent Valuation (CV) surveys and can impact their reliability. This paper contributes to the extensive debate on WTP (Willingness To Pay) elicitation formats by assessing whether the Circular Payment Card (CPC) can reduce anchoring on respondents' previous answers under multiple elicitation questions. This new format uses a visual pie-chart representation without start or end points: respondents spin the circular card in any direction until they find the section that best matches their WTP. We used a CV survey based on two ways of reducing risks associated with flooding, each randomly presented first to half of the respondents, to test the absolute performance of CPC. We presented a second survey on two social insurance schemes for subjects currently uninsured to respondents randomly split into three subgroups. Each group's WTP was elicited using one of three formats: Open-Ended (OE), standard Payment Card (PC) and the new CPC. The two insurance schemes were always proposed in the same order, and we assessed the relative performance of CPC by comparing anchoring across respondents. Our results provide evidence that CPC is likely to reduce anchoring in multiple elicitation questions and that respondents may rely on different heuristic decisions when giving WTP in the OE and in the two PC formats.
\end{abstract}

\section{Introduction}

Stated preference methods are increasingly used to inform public policies or company strategies when market prices cannot be observed directly. Examples include surveys dealing with non market values (in health, environment, education or transport) or with products not yet available on marketplaces (in marketing, finance or consumer research). Values are obtained either by choice modelling, i.e. analysing choices from several sets of alternatives, or by contingent valuation (CV), i.e. eliciting maximum willingness to pay (WTP) for a given level of good proposed in a hypothetical scenario.

Since respondents to CV surveys rely solely on a hypothetical scenario and an elicitation format when making their decision, the design of these components may affect stated WTP. The format needs to be appropriate, to ensure that CV surveys reveal respondents' "true" unobserved WTP values. In terms of the hypothetical scenario, this can generally be achieved by following practitioner guidelines and by doing careful pre-tests. However, although widely discussed in the literature, none of the existing elicitation formats appears clearly to outperform the others (see Mitchell and Carson, 1989; Carson and Groves, 2011). Choice of elicitation format is likely to impact the quality and quantity of WTP information collected, as well as to introduce potential errors/biases.

In particular, elicitation formats that rely on closed-ended answers may encourage the anchoring of respondents' WTP on the bids offered (Boyle et al., 1997; Herriges and Shogren, 1996). A variant of the Payment Card (PC) - referred to as the Circular PC (CPC) - was

\footnotetext{
* Corresponding author. AMSE, 5 boulevard Maurice Bourdet CS50498 13205 Marseille cedex 01, France.

E-mail addresses: victor.champonnois@univ-amu.fr (V. Champonnois), olivier.chanel@univ-amu.fr (O. Chanel), khaled.makhloufi@hotmail.com (K. Makhloufi).
} 
recently proposed (Chanel et al., 2013) to limit such anchoring. By using a visual pie-chart representation without start or end points (see Fig. 1), it helps eliminate starting-bid and middle-card biases, and strongly reduces the range effect. This new format has been compared favourably to two of the most common elicitation formats: the Open Ended (OE) and PC (Chanel et al., 2017).

This paper seeks to contribute to the methodological literature on WTP elicitation formats by testing CPC's ability to limit anchoring on the respondent's previous answers under multiple CV elicitation questions. We use the results of two CV surveys to assess both the absolute and the relative ability of the CPC format to cope with such anchoring. The first survey proposes two successive scenarios for flood-related risk reduction and exploits the random assignment of scenario order over the sample of respondents to test the format's absolute ability. We expect to find no evidence of anchoring on the first elicited WTP. The second survey successively elicits WTP for first, health and second, pension insurance schemes over the whole sample. Keeping the order unchanged, we randomly use a different elicitation format (OE, PC or CPC) for each of three sub-groups to test the relative ability of the CPC format w.r.t. the two others. We expect to find less anchoring on first WTP with the CPC format than with the two other formats.

The remainder of the paper is structured as follows. Section 2 describes the anchoring issues in CV and details the new format proposed, while Section 3 explains the empirical strategy. Section 4 tests for anchoring in a survey dealing with two ways of reducing risks associated with flooding, while Section 5 tests for anchoring in a survey dealing with two social insurance schemes for respondents currently uninsured. Section 6 discusses and concludes.

\section{Anchoring and the elicitation format}

\subsection{Anchoring issues in CV surveys}

Anchoring belongs to the larger class of implied value cues that directly lead to respondents' answers being sensitive to framing effects in ascending vs. descending bidding games (DeShazo, 2002), to a greater tendency to "yea/nay" saying in dichotomous choice (DC) questions (Kanninen, 1995; Chien et al., 2005) or to incentive incompatibility in multiple DC questions (Whitehead, 2002). A first type of anchoring arises when the respondent tends to anchor his/her stated WTP on the bid(s) offered during the elicitation step, being influenced by starting values (the starting point bias first evoked by Tversky and Kahneman, 1974; in psychology), follow-up values (Araña and León, 2007) and the range and the centring of bids (Covey et al., 2007). When WTP answers include an anchoring effect, "true" unobserved WTP differs from stated WTP in a non-random way, making it unsound to base any decision on such values.

It is worth noting that the anchoring tendency is partly unconscious. It has been observed in psychological studies eliciting objective quantities (e.g. the length of the Amazon, the yearly average mileage travelled by car or the number of physicians in the local yellow pages) even when respondents know that the numbers proposed are random and unrelated to the good (O'Conor et al., 1999; Tversky and Kahneman, 1974; Wilson et al., 1996). Anchoring is especially prevalent when preferences regarding the good are uncertain, due to poor definition or too limited knowledge. Flachaire and Hollard (2007), for instance, develop a model in which the bids proposed during the survey help respondents reduce uncertainty, resulting in a stronger effect on the initial bid than on subsequent bids. Overall, this type

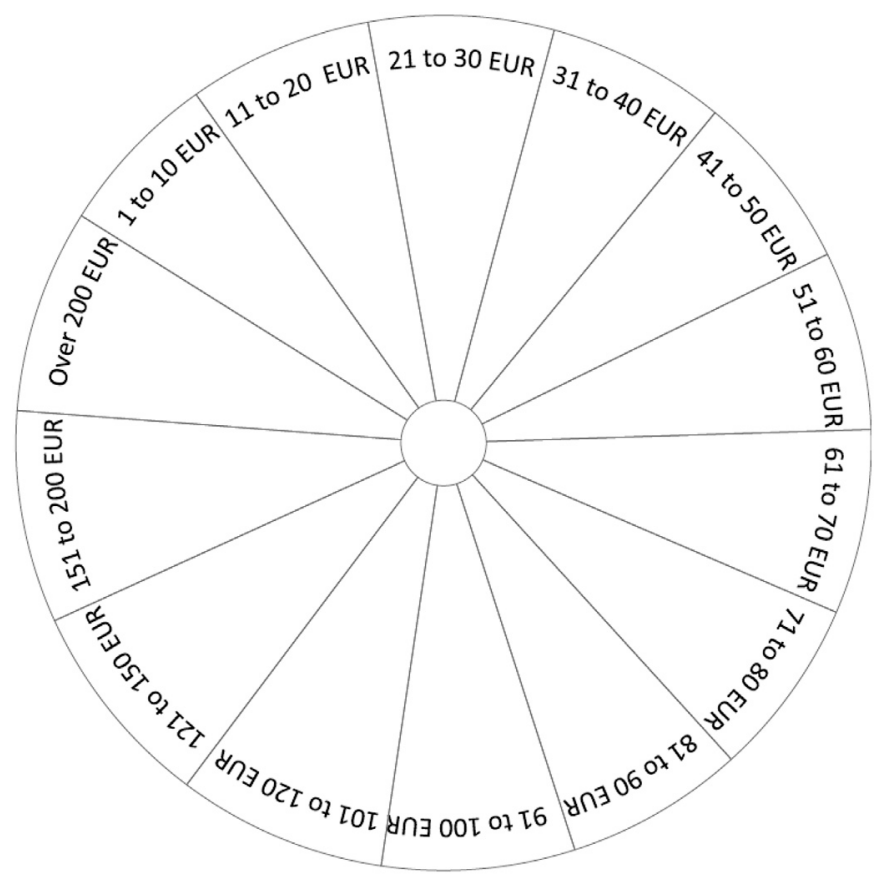

Fig. 1. Circular payment card used in the Flooding survey (English translation). 
of anchoring arises when the bid proposed (or any number proposed) during the elicitation process is considered as providing an indication of the value of the good (i.e., a cognitive anchor).

A second type of anchoring arises when multiple WTPs are elicited within a single CV survey implicitly assuming that respondents' answers are unaffected (see the question order issue in Boyle et al., 1993). This is sometimes done when the choice modelling approach is not methodologically feasible, or as a way of reducing survey costs or exploring various alternatives within the same scenario. Although multiple eliciting has advantages, like explicitly offering potential substitutes for the good valued (see Luchini et al., 2003), respondents may be influenced by their prior answers (Payne et al., 2000; Longo et al., 2015). They may also have difficulties with the alternative-specific cognitive assessment for each valuation question, i.e. be unable to construct the appropriate reference framework for each question (Selart, 1996). The consequence is a deliberate or unconscious tendency for respondents to self-anchor on their own previously stated WTP. This type of anchoring is different from the position effect in a top-down or a bottom-up design, in which a composite good is valued either directly or as a package built from a smaller subset or extracted from a larger multipack good (Powe and Bateman, 2003; Veisten et al., 2004). It is also different from a nested effect, either true (when one good is a subset of another, Carson and Mitchell, 1995) or perceived by the respondents (when one good is an improved version of another, De Ridder and De Graeve, 2005).

In this article, we focus on the second type of anchoring: a tendency to rely on one's own previous answers in multiple elicitation questions, without fully considering what makes the goods assessed differ across questions. We assess how a recently proposed variant of the $\mathrm{PC}$ - the $\mathrm{CPC}$ - performs with respect to this type of anchoring, using the results from two empirical multiple elicitation CV surveys.

\subsection{A new variant of the PC: the CPC}

Despite recent improvements (Wang, 1997; Cook et al., 2012; Mahieu et al., 2017) the PC format still presents disadvantages, chiefly the risk of implied value cues from the range of the bid interval, the starting values and the position of the bids. Chanel et al. (2013) recently introduced a variant of the PC: the CPC. It uses a visual representation of a circular card with no predetermined start or end points, no top or bottom, no left or right (see Figs. 1 and 2 for two examples). The interviewer asks the respondent to think about his/her maximum WTP, and then presents the CPC in a random position to help her/him in the elicitation process. Respondents are asked to spin it until they find the section that best corresponds to their WTP to benefit from the improvement proposed in the scenario. The text containing the WTP values is curved around the circle to allow easy handling and spinning, with no predetermined direction of rotation. The respondent is then asked which section corresponds to his/her WTP; there may also be an OE follow-up question to elicit a more precise WTP.

Chanel et al. (2017) establish the advantages of the CPC over the standard PC on a single elicitation question: it helps eliminate starting-bid bias (because each section is equally likely to be seen at first glance) and middle-card bias (by construction), and strongly reduces the range effect associated with the bids chosen (the succession of bid ranges mimics a continuous distribution). Since the respondent has to spin the circular card to reach the section corresponding to his/her WTP, both cognitive and (a small) physical effort

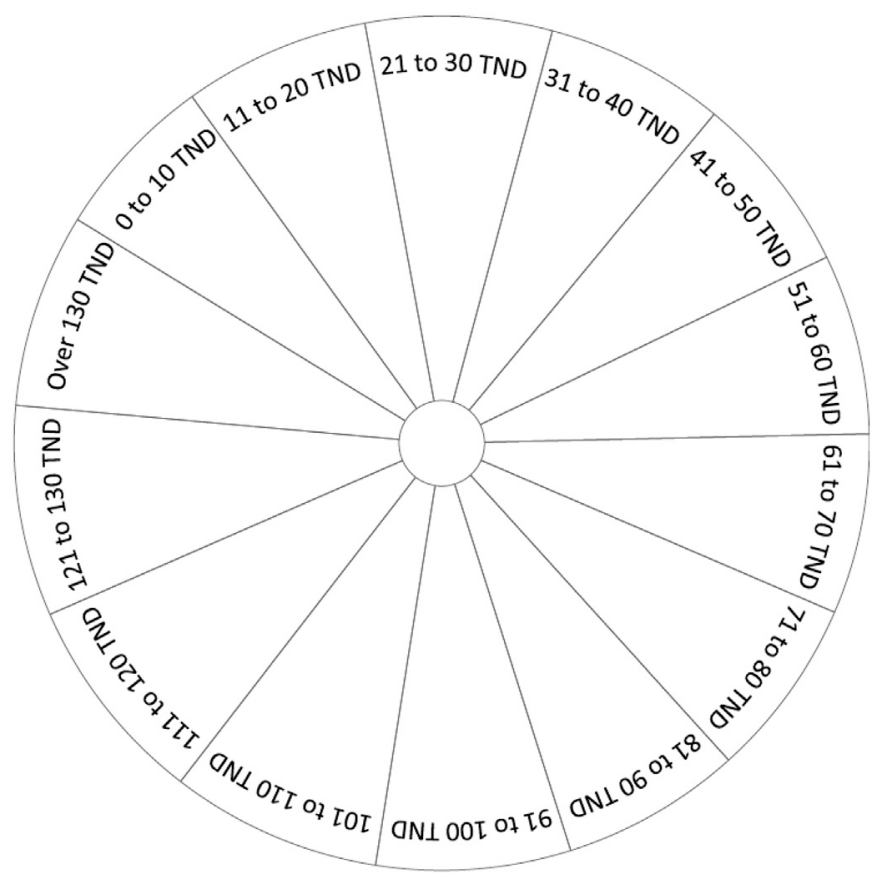

Fig. 2. Circular payment card used in the Social Ins. Survey (English translation). 
are involved. This extends the cognitive process from the pure reflection needed to choose a value to the motor skills needed to spin the CPC. These 'efforts', repeated for each elicitation question, may increase the respondent's engagement in the elicitation process. Because the interviewer presents the CPC in a new random position for every question, respondents are assumed to be less likely to anchor on their own previous WTP when answering a subsequent WTP question in multiple elicitation surveys. To test this, we used two empirical CV studies.

\section{Empirical strategy}

We used the results of two CV surveys - on flooding and on social insurance - to assess both the absolute and the relative ability of the $\mathrm{CPC}$ format to cope with the anchoring issue under multiple elicitation questions.

\subsection{Testing the CPC format's absolute anchoring reduction potential}

In the first CV survey, residents of France's Provence Alpes Côte d'Azur (PACA) region with differing degrees of flood-risk exposure were presented with two successive scenarios for flood-related risk reduction (Protective Devices or Insurance). Each scenario was presented in first position to a randomly chosen half of the sample, and all respondents' WTPs were elicited using the CPC (see Fig. 1). Consequently, through random assignment of scenario ordering over the sample, this survey offers a test of the absolute ability of CPC to cope with anchoring, by examining the relationship between WTP elicited and scenario ordering. Let us denote the $j$ th elicited WTP for scenario $k$ by $W T P_{k j}$ with $j=1,2, k=A, B$, and omit the respondent's index $i$ to lighten notations.

First, we perform unconditional analyses. We start by checking whether WTPs differ according to respondent group (WTP $P_{A 1}$ and $W T P_{B 2}$ pooled vs. $W T P_{B 1}$ and $W T P_{A 2}$ pooled) and scenario $\left(W T P_{A 1}\right.$ and $W T P_{A 2}$ pooled vs. $W T P_{B 1}$ and $W T P_{B 2}$ pooled). We then check for the presence of multiple anchoring by looking at whether, for a given scenario, WTPs are the same when stated in first position (no anchoring) and in second position (after potential anchoring): $\mathrm{WTP}_{\mathrm{A} 1}$ vs. $\mathrm{WTP}_{\mathrm{A} 2}$ and $\mathrm{WTP}_{\mathrm{B} 1} \mathrm{vs.}_{\mathrm{WTP}} \mathrm{P}_{\mathrm{B} 2}$.

We use four different equality tests to compare WTPs, paired or unpaired depending on the pooling applied. We perform a Welch (1947)'s $t$-test assuming that the mean WTPs are the same. Then we test whether the median WTPs are the same using a Chi-square nonparametric test of independence. Finally we use two other non-parametric tests of the equality of the distribution: the Wilcoxon ranksum and the Kolmogorov-Smirnov tests.

Second, we check whether the unconditional results hold when overall potential heterogeneity of respondents is taken into account by estimating the anchoring effect with the following model for both scenarios (Models 1 and 2):

$$
W T P_{k i}=\alpha \operatorname{Order}_{i}+x_{i}^{\prime} \beta+u_{i} k=1,2, \quad i=1, \cdots, n .
$$

where $x_{i}$ is the vector of individual covariates, $\beta$ is a vector of coefficients, $\operatorname{Order}_{i}$ is a dummy accounting for the order of the scenarios, $\alpha$ is the associated coefficient and $u_{i}$ is an error term. Testing for the null hypothesis $\alpha=0$ allows us to detect a potential anchoring effect, while controlling for observed characteristics.

\subsection{Testing the CPC format's relative anchoring reduction potential}

The second CV survey successively asked uninsured Tunisians their WTP for health and pension insurance schemes that could be made available to them. In this survey, although the health insurance scheme was always proposed first (scheme A), each of three subgroups of equal size was randomly assigned to one elicitation format: OE, PC or CPC. Consequently, this survey offers the opportunity to test the relative ability of the CPC format to cope with multiple anchoring w.r.t. the two standard formats.

We analyse differences in WTP between respondents, to explore the tendency to anchor - both specific to each elicitation format and linked to the first elicited WTP - while controlling for WTP determinants. We focus below on the anchoring of WTP for the pension scheme (B) on WTP for the health scheme (A), accounting for the impact of the elicitation formats $l=O E, P C, C P C$ (see for instance Luchini et al., 2003; or Protière et al., 2004; for a more complete treatment of interdependencies involving information delivered). We proceed in two ways. First, we introduce WTP for scheme A $\left(W T P_{A i}\right)$ and dummy-specific terms for the elicitation format $\left(E l i c i t a t i o n_{l i}\right)$ (Model 3):

$$
W T P_{B i}=x_{i}^{\prime} \beta+\delta W T P_{A i}+\varepsilon \text { Elicitation }_{l i}+u_{i}
$$

Then, we replace the $W T P_{A i}$ variable by specific interaction terms $W T P_{A i} x$ Elicitation li to account for an elicitation format-specific anchoring effect on scheme A (Model 4):

$$
W T P_{B i}=x_{i}^{\prime} \beta+\varepsilon \text { Elicitation }_{l i}+\phi W T P_{A i} \times \text { Elicitation }_{l i}+u_{i}
$$

\subsection{Methodological issues common to both surveys}

Because we are concerned here with the ability of the CPC format to reduce anchoring under multiple elicitation questions, we restrict our analysis to respondents actually exposed to the elicitation format. Consequently, in both surveys, respondents answering "No" to a prior willingness-to-join question (protest and true null responses) are removed from the samples. In addition, we restrict the 


\begin{tabular}{|c|c|c|c|c|}
\hline \multirow[t]{2}{*}{ Test of equality } & \multirow{2}{*}{$\begin{array}{l}\text { Group effect } \\
\mathrm{WTP}_{\mathrm{A} 1} \text { and } \mathrm{WTP}_{\mathrm{B} 2} \mathrm{vs} . \\
\mathrm{WTP}_{\mathrm{B} 1} \text { and } \mathrm{WTP}_{\mathrm{A} 2}\end{array}$} & \multirow{2}{*}{$\begin{array}{l}\text { Scenario effect } \\
\mathrm{WTP}_{\mathrm{A} 1} \text { and } \mathrm{WTP}_{\mathrm{A} 2} \mathrm{vs} . \\
\mathrm{WTP}_{\mathrm{B} 1} \text { and } \mathrm{WTP}_{\mathrm{B} 2}\end{array}$} & \multicolumn{2}{|l|}{ Anchoring effect } \\
\hline & & & $\mathrm{WTP}_{\mathrm{A} 1}$ vs. $\mathrm{WTP}_{\mathrm{A} 2}$ & $\mathrm{WTP}_{\mathrm{B} 1}$ vs. $\mathrm{WTP}_{\mathrm{B} 2}$ \\
\hline Mean ( $t$-test) & .9011 & .0076 & .9088 & .7499 \\
\hline Median (non parametric test) ${ }^{\mathrm{a}}$ & .231 & .0725 & .595 & .445 \\
\hline Distribution (Wilcoxon rank-sum test) & .7394 & .0298 & .9447 & .5858 \\
\hline Distribution (Kolmogorov Smirnov test) ${ }^{\mathrm{b}}$ & .787 & - & .742 & .729 \\
\hline
\end{tabular}

${ }^{\text {a }}$ WTPs equal to the median are equally split between the two groups.

b No standard KS test is available for paired data.

samples to respondents who provide valid WTP for each multiple elicitation question.

Although it is common in the literature to use increasingly spaced bid amounts with the standard PC, we choose equally spaced amounts for our CPC, both based on pre-tests and as inherent to the design (better mimicking a continuous distribution). Finally, regressions use the middle of the bid-range elicited for the PC and CPC formats (as in Cameron and Huppert, 1989; Yang et al., 2012). In the social insurance survey, this enables a single model to be used to elicit WTP via three formats. Note that interval regression models (Wooldridge, 2002; Anderson and Mellor, 2009) that account for differences in the type of WTP elicited have also been estimated. They yield very similar results, whether they use point estimate both in the OE format and the OE follow-up question of the CPC format and interval with two specified thresholds for the PC format, or point estimate for the OE format and interval for the PC and CPC formats (details upon request).

\section{Evidence on the CPC'S absolute anchoring reduction potential}

\subsection{Survey design of the CV survey on flooding}

The first CV survey was conducted through face-to-face interviews in April-June 2012 with inhabitants living in four municipalities of Southeastern France. Two scenarios for flood risk reduction were presented to each respondent, in the spirit of Deronzier and Terra (2006) (see Appendix A for details). The first one (Protective Devices) proposed a collective action consisting in funding municipalitylevel protective devices; the WTP stated by the respondents covered both the material and the psychological costs of flooding. The second scenario (Insurance) proposed a payment for insurance against the financial risk related to flooding; the WTP covered only material damage. The sample was randomly divided into two groups differing in scenario presentation order. This enabled us to disentangle the impact of the scenario (Insurance vs. Protective Devices) from the impact of the order of presentation (First vs. Second).

The initial sample was composed of 599 adults representative of the PACA population in terms of three stratification variables (age, gender, and profession) and differing with respect to the flood risk inherent in their place of residence. Of the municipalities, Miramas had never been flooded and was not in a flood plain, Berre l'Etang had never been flooded but was located in a potentially risky area, Vaison-la-Romaine was flooded in 1992 (41 dead or missing), Draguignan was flooded in 2010 (25 dead or missing). All respondents from previously flooded municipalities had to be living there when the flood occurred. Questions covered socio-demographic variables, preferences regarding time and risk, flood risk perception, information and behaviours regarding flood risk (see Appendix B for a description of the variables). 200 respondents answered "No" to the willingness-to-join question for both scenarios and 132 for at least one scenario, leaving us with 277 respondents who encountered the CPC twice.

\subsection{Results}

We first conduct the four equality tests presented in section 3.1 on pooled WTPs, to check whether the WTPs differ significantly depending on respondent's group and scenario (see Table 1). Whatever the test of equality, the null assumption of equality of WTP by group cannot be rejected (lowest p-value $=.231$ ), but the null assumption by scenario is always rejected: WTPs for Insurance are higher than for Protective Devices. The absence of any group effect rules out a spurious association with anchoring effect through presentation order, while a significant difference across scenarios leaves room for potential anchoring. Because WTP for Insurance is significantly higher than for Protective Devices, in presence of multiple anchoring we expect the second WTP elicited to be anchored on the first and hence both a lower WTP for Insurance and a higher WTP for Protective Devices when elicited second. The last column in Table 1 presents the results of the test of multiple question anchoring. Whatever the equality test, we never reject the null assumption of equality (lowest $\mathrm{p}$-value $=.445$ ).

Then, to more accurately account for individual characteristics, we estimate Eq. (1) by regressing the WTPs on a set of covariates, plus a dummy controlling for scenario ordering. First, we test for independence of covariates across groups (see the p-values in Appendix B) and reject independence only for preference for the Protective Devices scenario (PrefProtective), despite random assignment across respondents. Consequently, we force this variable into the parsimonious model presented in Table 2, which keeps only variables significant at $10 \%$ threshold. Then, we use cluster-robust standard errors at the municipality level to account for potential correlation due 
Table 2

Model estimates for the CV survey on Flooding.

\begin{tabular}{|c|c|c|}
\hline Variables & $\begin{array}{l}\text { Model } 1 \\
\text { WTP for Insurance }\end{array}$ & $\begin{array}{l}\text { Model } 2 \\
\text { WTP for Protective Devices }\end{array}$ \\
\hline $\operatorname{Order}(=1)$ & $4.004(.829)$ & $-7.757(.575)$ \\
\hline \multicolumn{3}{|l|}{ Socio demographic } \\
\hline Income & $0.029(<.001)$ & $0.031(.017)$ \\
\hline \multicolumn{3}{|l|}{ Flood-related risk } \\
\hline Inform $(=1)$ & $59.366(.043)$ & $51.78(<.001)$ \\
\hline NbrInfo & $20.91(<.001)$ & $18.725(<.001)$ \\
\hline ProbaFlood & $8.152(<.001)$ & $6.361(<.001))$ \\
\hline PrefProtective $(=1)$ & $21.62(.590)$ & $17.40(.464)$ \\
\hline \multicolumn{3}{|l|}{ Attitudinal } \\
\hline Impatience & $-9.036(.084)$ & $-7.054(.025)$ \\
\hline RiskTolerance & $51.74(<.001)$ & $29.67(<.001)$ \\
\hline Constant & $-106.6(<.001)$ & $-114.5(<.001)$ \\
\hline Observations & 263 & 263 \\
\hline Adjusted $\mathrm{R}^{2}$ & 0.176 & 0.291 \\
\hline
\end{tabular}

to survey design (Bhattacharya, 2005) and unobservable characteristics. Moreover, we test for endogeneity between the perceived likelihood of being flooded in the next 10 years (ProbaFlood) and each of the WTPs. ${ }^{1}$ We cannot reject endogeneity (p-values <.05), so we use instrumental variable (IV) estimators to obtain unbiased estimates.

The results in Table 2 confirm that scenario order is never significant: whatever the scenario order, we cannot reject the absence of anchoring (p-value greater than .575). This also holds in strictly parsimonious models without forcing PrefProtective (not shown, p-value greater than .626) as well as in all models estimated with different sets of control variables used as robustness checks (see Appendix C, pvalue greater than .299).

The effects of individual determinants have the expected sign and are of comparable significance across models. Income has a positive effect of comparable magnitude in explaining both WTPs. Other standard socio-demographic variables (Male, Age, Couple, Education, Child) are not significant at the 10\% threshold and are hence not shown in Table 2, meaning they are weaker determinants of WTPs than flood-related variables. Indeed, respondents' information about flood risk (Inform and NbrInfo) is a significant and positive determinant of their level of WTP, as is the perceived likelihood of being flooded in the next 10 years (ProbaFlood). Impatience has an intuitive negative effect. Finally, RiskTolerance has a counter-intuitive positive effect, which suggests that risk aversion elicited through lotteries is a poor predictor of risk behaviours elicited in real-life situations.

P-values in parentheses are computed with cluster-robust standard errors by municipality. In each model, the variables used to explain ProbaFlood in the first stage (not shown) are all exogenous variables plus the following instruments: municipality dummies and HousingRisk.

Overall, both the unconditional and the conditional tests provide evidence of absence of multiple question anchoring. However, because this CV survey on Flooding exclusively uses the CPC format, we cannot with certainty attribute the absence of anchoring to the use of CPC. It may be due to other aspects of the survey (no huge difference in WTP across scenarios, enough time given to respondents to set their WTP at each question, etc.). We thus turn to the CV survey on Social Insurance to isolate the effect of CPC on anchoring by comparing it with two other elicitation formats within a multiple question framework.

\section{Evidence on the CPC'S relative anchoring reduction potential}

\subsection{Survey design of the CV survey on social insurance}

The second CV survey was conducted between August and September 2013, on Tunisian citizens not covered by - nor benefiting from - any social insurance scheme, i.e. more likely to be young, unemployed or informal workers (see Abu-Zaineh et al., 2013, 2014; Makhloufi et al., 2015). Two sampling locations in eight Tunisian governorates were consequently chosen so as to target these citizens: the "Souk", characterized by the high presence of informal activities, and the public squares where many peaceful demonstrations involving unemployed youths were organized after the so-called "Arab Spring".

Among the initial sample of 456 respondents surveyed using face-to-face interviews, 30 refused to answer the CV module. The remaining 426 were randomly split into three mutually exclusive and equal groups differing in the WTP elicitation format used (OE, PC and CPC, see Fig. 2 for the latter). All respondents answered the same questionnaire (pre-tested for wording and choice of the number, range and values of the bids).

The valuation task started by asking respondents their willingness-to-join and their quarterly WTP for a Voluntary pre-payment Health Insurance Scheme (VHIS) made available to them. This was similar to the existing mandatory health insurance scheme currently run by the National Health Insurance Fund (known as "Caisse Nationale d'Assurance Maladie", CNAM, see Appendix D).

Then, all respondents were asked their willingness-to-join and their quarterly WTP for a Voluntary Pension Insurance Scheme (VPIS)

1 We thank a reviewer for drawing our attention to this issue. 
Table 3

\begin{tabular}{|c|c|c|}
\hline Variables & $\begin{array}{l}\text { Model } 3 \\
\text { WTP for VPIS }\end{array}$ & $\begin{array}{l}\text { Model } 4 \\
\text { WTP for VPIS }\end{array}$ \\
\hline Elicitation_OE $(=1)$ & $0.533(.887)$ & $-14.885(.054)$ \\
\hline Elicitation_PC $(=1)$ & $-5.123(.187)$ & $-11.024(.078)$ \\
\hline Elicitation_CPC $(=1)$ & (ref) & (ref) \\
\hline WTP-VHIS & $0.526(.003)$ & - \\
\hline WTP-VHIS $x$ Elicitation_OE & - & $0.708(.021)$ \\
\hline WTP-VHIS $x$ Elicitation_PC & - & $0.474(.012)$ \\
\hline WTP-VHIS $\times$ Elicitation_CPC & - & $0.337(<.001)$ \\
\hline \multicolumn{3}{|l|}{ Survey } \\
\hline Interviewer \#2 $(=1)$ & $-21.213(.002)$ & $-19.531(.005)$ \\
\hline Interviewer \#5 (=1) & - & $8.528(.001)$ \\
\hline \multicolumn{3}{|l|}{ Socio demographic } \\
\hline Income & - & $0.0083(.036)$ \\
\hline Age & $1.667(.085)$ & $1.524(.059)$ \\
\hline$(A g e)^{2}$ & $-0.021(.084)$ & $-0.0190(.066)$ \\
\hline Rural $(=1)$ & $-8.646(.033)$ & $-7.921(.058)$ \\
\hline $\operatorname{NoSchool}(=1)$ & $-22.280(.005)$ & $-17.477(.016)$ \\
\hline \multicolumn{3}{|l|}{ Health respondent } \\
\hline Outpatient $(=1)$ & $9.924(.027)$ & $7.402(.060)$ \\
\hline Constant & $-4.436(.770)$ & $-0.667(.955)$ \\
\hline Observations & 203 & 203 \\
\hline Adjusted $\mathrm{R}^{2}$ & .5045 & .5314 \\
\hline
\end{tabular}

Cluster-robust standard errors are used at interviewer level. P-values in parentheses.

available in addition to the VHIS. This also mimicked the existing mandatory retirement scheme for the self-employed entitled to the National Social Security Fund (known as "Caisse Nationale de Sécurité Sociale", CNSS, see Appendix D). 26 respondents answered "No" to the willingness-to-join question for both schemes, 197 for at least one scheme, leaving us with 203 respondents exposed twice to the elicitation question.

The lack of random assignment in the scenario prevented us from using the approach used in the Flooding survey, but the random assignment of the elicitation formats enabled us to test relative CPC performance regarding multiple anchoring.

\subsection{Results}

We explicitly take into account the potential interdependencies/anchoring between elicitations for the two social insurance schemes. Appendix E provides descriptive statistics on respondents' WTPs, socio-economic, socio-demographic and health characteristics (see Chanel et al., 2017 for a detailed presentation of the survey).

Results of the parsimonious (i.e. keeping only variables significant at $10 \%$ threshold) OLS models are reported in Table 3 . We use cluster-robust standard errors at interviewer level to account for potential correlation of unobservable characteristics specific to the interviewer or to the geographical area the interviewer was assigned to. ${ }^{2}$ Model 3 estimates Eq. (2) and shows a significant and positive anchoring effect on the previously elicited WTP with a coefficient of about 0.526 ( $\mathrm{p}$-value $=.003$ ), which means that, on average, respondents anchor at 53\% on their WTP previously elicited for VHIS. The OE and PC formats do not lead to WTPs that are significantly different from those elicited using the CPC format.

In Model 4, we replace the overall anchoring term by three elicitation format-specific anchoring terms, and we find a significant and positive effect for each of them, larger for OE $(0.708$, p-value $=.021)$ than for CPC $(0.337, p$-value $<.0001)$ and PC $(0.474$, pvalue $=.012$ ). The difference in anchoring is significant between $\mathrm{OE}$ and PC estimates (p-value $=.0607$ ) and $\mathrm{OE}$ and $\mathrm{CPC}$ ( $\mathrm{p}$ value $=.0966$ ) but not between CPC and PC (p-value $=.1949$ ).

Regarding the determinants, we find a positive effect of household income on WTP in Model 4, and evidence of interviewer effects in both models. Respondent's age has a significantly positive quadratic effect (with a maximum at 39 and 40, depending on the model), while education has a positive effect: NoSchool decreases WTP. Finally, living in a rural governorate negatively affects WTP, and the effect of having at least one outpatient consultation appears positive. Sensitivity analyses are provided in Appendix F, with models that consecutively use different sets of control variables for Models 3 and 4: survey-specific, socio-demographic, specific to respondent's health, specific to the health of respondent's family members and others (respondent's risk aversion and reasons for not yet having a health insurance scheme). They confirm the results obtained with the parsimonious models.

\section{Discussion}

In the CV survey on Flooding, which uses the CPC format alone but randomly changes the order of scenario presentation, we found

\footnotetext{
${ }^{2}$ Only five interviewers covered the eight sample locations, generating strongly imbalanced distributions of the Rural, Disadvantaged governorate and Sample point variables by interviewer. To avoid high collinearity, we do not use these three spatially related variables in the same model.
} 
no evidence of anchoring on the first elicited WTP. In the CV survey on Social Insurance, which randomly uses three elicitation formats, we found greater anchoring on the first WTP with the OE format than with the two PC-type formats. This suggests that respondents may rely on different heuristic decisions when stating WTP in the OE and in the two PC formats (Hanemann, 1996; Welsh and Poe, 1998; Frör, 2008). A possible explanation is that answering an OE question is not typical of purchasing decisions, because the respondent has to set the price. S/he thus needs to reflect deeply before giving an amount. Faced with a second question related to the first, s/he may therefore rely on his/her first answer, giving an amount related to the previous one rather than again reflecting deeply. The PC formats, by providing the amounts, along with a visual aid, mimic real-life decisions (i.e. as price-taker), thereby facilitating the construction of the evaluation. This is also consistent with Van Exel et al. (2006): "the anchoring and adjustment process often involves a great deal of inertia. People tend to hold on to their anchor and adjustment is typically insufficient, so that the final estimate is pulled toward the anchor (p. 841)". Thus, when there is a second question, it is easier to change the amount by assessing how much better (or worse) the second good proposed is than the first one. The lesson here is that PC formats need to include provisions to limit anchoring effects from multiple successive elicitation questions. The CPC, being presented in a new random position to each respondent at every question, is a first attempt to limit anchoring. Longo et al. (2015) suggest offering respondents the opportunity to revise their WTP at the end of the multiple elicitation sequence, to help them better account for differences across the goods assessed.

A survey specifically designed to test whether the CPC reduces anchoring bias in multiple question CV surveys would use several elicitation formats, including several versions of the CPC (i.e. various settings of bid amounts, numbers, spacing (constant or increasing), ordering (ordered vs. non ordered)), with several scenarios successively proposed in varying order. This would however require a large respondent sample to obtain sufficient statistical accuracy, and would be expensive. Incidentally, a larger sample size would allow multilevel models to be used, thus better accounting for clustering within a community of respondents (by city in the flooding survey, or by governorate in the social insurance survey). The aim here was more modest: to assess, by exploiting the results of two already existing surveys, whether the CPC helps reduce anchoring. This paper provides evidence that it does.

Finally, it should be noted that in both applications, our analyses focus exclusively on differences across elicitation formats with respect to anchoring. Because respondents answered a willingness-to-join question before the elicitation format was used, we purposely only consider those who did not answer 'No'. However, while this is consistent with our intentions, respondents answering 'No' should be accounted for in any modelling aimed at predicting WTP, in particular by disentangling protest WTP from true null WTP based on (closed-ended) debriefing questions on the reasons for refusing to join.

\section{Acknowledgments}

This research was carried out thanks to the A*MIDEX grant AMSE (ANR-11-IDEX-0001-02) and OT-Med (ANR-11-LABEX-0061) funded by the "Investissements d'Avenir" French Government program, as well as the programs Riskemotion (ANR-08-RISKNAT-00701) and GREEN-Econ (ANR-16-CE03-0005), all managed by the French National Research Agency (ANR). We thank Dominique Ami, Ana Bobinac, Brett Day, Pierre-Alexandre Mahieu and Stéphane Luchini for relevant comments and suggestions on an earlier version, three anonymous reviewers for helping us improve the paper and Marjorie Sweetko for her thorough re-reading of the English. We are also grateful to all the respondents that answered our questionnaires, and to the interviewers.

\section{Glossary}

CNAM Caisse Nationale d'Assurance Maladie

CNSS Caisse Nationale de Sécurité Sociale

CPC Circular Payment Card

CV Contingent valuation

DC dichotomous choice

IV instrumental variables

OE Open-Ended

PACA Provence Alpes Côte d'Azur

PC Payment Card

TND Tunisian Dinar

VHIS Voluntary Health Insurance Scheme

VPIS Voluntary Pension Insurance Scheme

WTP Willingness to Pay

\section{Appendix A-F. Supplementary data}

Supplementary data related to this article can be found at https://doi.org/10.1016/j.jocm.2018.04.005.

\section{References}


Abu-Zaineh, M., Arfa, C., Ventelou, B., Romdhane, H.B., Moatti, J.-P., 2014. Fairness in healthcare finance and delivery: what about Tunisia? Health Pol. Plann. 29 (4), $433-442$.

Anderson, L.R., Mellor, J.M., 2009. Are risk preferences stable? Comparing an experimental measure with a validated survey-based measure. J. Risk Uncertain. 39, $137-160$.

Araña, J.E., León, C.J., 2007. Repeated dichotomous formats for eliciting Willingness to Pay: simultaneous estimation and anchoring effects. Environ. Resour. Econ. 36 (4), 75-497.

Bhattacharya, D., 2005. Asymptotic inference from multi-stage samples. J. Econom. 126, 145-171.

Boyle, K., Johnson, F.R., McCollum, D., 1997. Anchor and adjustment in single-bounded dichotomous-choice questions. Am. J. Agric. Econ. 79 (5), 1495-1500.

Boyle, K., Welsh, M., Bishop, R., 1993. The role of question order and respondent experience in contingent-valuation studies. J. Environ. Econ. Manag. 25, 80-99.

Cameron, T.A., Huppert, D.D., 1989. OLS versus ML estimation of non-market resource values with payment card interval data. J. Environ. Econ. Manag. $17,230-246$.

Carson, R.T., Mitchell, R.C., 1995. Sequencing and nesting in contingent valuation surveys. J. Environ. Econ. Manag. 28 (2), $155-173$.

Carson, R.T., Groves, T., 2011. Incentive and information properties of preference questions commentary and extensions. In: Bennett, J. (Ed.), International Handbook on Non-market Valuation. Edward Elgar, Northampton.

Chanel, O., Chichilnisky, G., Massoni, S., Vergnaud, J.-C., Vincent Lyk-Jensen, S., 2013. Décision en présence d'incertitude et d'émotions face à des risques de catastrophes naturelles. Final Report ANR-08-RISKNAT-007-01. Greqam, Marseille.

Chanel, O., Makhloufi, K., Abu-Zaineh, M., 2017. Can a circular payment card format effectively elicit preferences? Evidence from a survey on mandatory health insurance scheme in Tunisia. Appl. Health Econ. Health Pol. 15 (3), 385-398.

Chien, Y.L., Huang, C., Shaw, D., 2005. A general model of starting point bias in double-bounded dichotomous contingent valuation surveys. J. Environ. Econ. Manag. $50,362-377$

Cook, J., Jeuland, M., Maskery, B., Whittington, D., 2012. Giving stated preference respondents "time to think": results from four countries. Environ. Resour. Econ. 51 (4), 473-496.

Covey, J., Loomes, G., Bateman, I., 2007. Valuing risk reductions: testing for range biases in payment card and random card sorting methods. J. Environ. Plann. Manag. 50 (4), 467-482.

De Ridder, A., De Graeve, D., 2005. Order bias in estimates of willingness to pay for drugs to treat attention-deficit/hyperactivity disorder. Eur. J. Health Econ. 6, $146-151$.

Deronzier, P., Terra, S., 2006. Bénéfices économiques de la protection contre le risque d'inondation. Document de travail D4E. Série Etudes 06-E05. MEDE, Paris.

DeShazo, J., 2002. Designing transactions without framing effects in iterative question formats. J. Environ. Econ. Manag. 43, 360-385.

Flachaire, E., Hollard, G., 2007. Starting-point bias and respondent uncertainty in dichotomous choice contingent valuation surveys. Resour. Energy Econ. 29 , 183-194.

Frör, O., 2008. Bounded rationality in contingent valuation: empirical evidence using cognitive psychology. Ecol. Econ. 68, 570-581.

Hanemann, W.M., 1996. Theory versus data in the contingent valuation debate. In: Bjornstad, J., Kahn, J.R. (Eds.), The Contingent Valuation of Environmental Resources: Methodological Issues and Research Needs. Elgar, Brookfield.

Herriges, J., Shogren, J., 1996. Starting point bias in dichotomous choice valuation with follow-up questioning. J. Environ. Econ. Manag. 30, $112-131$.

Kanninen, B., 1995. Bias in discrete response contingent valuation. J. Environ. Econ. Manag. 28, 114-125.

Longo, A., Hoyos, D., Markandya, A., 2015. Sequence effects in the valuation of multiple environmental programs using the contingent valuation method. Land Econ. 91 (1), 20-35.

Luchini, S., Protière, C., Moatti, J.-P., 2003. Eliciting several willingness to pay in a single contingent valuation survey: application to health care. Health Econ. 12, 51-64.

Mahieu, P.-A., Wolff, F.C., Shogren, J., Gastineau, P., 2017. Interval bidding in a distribution elicitation format. Appl. Econ. 49 (51), $5200-5211$.

Makhloufi, K., Ventelou, B., Abu-Zaineh, M., 2015. Have health insurance reforms in Tunisia attained their intended objectives? Int J Health Econ Manag 15 (1), $29-51$.

Mitchell, R.C., Carson, R.T., 1989. Using Surveys to Value Public Goods: the Contingent Valuation Method. Johns Hopkins University Press, Baltimore.

O'Conor, R.M., Johannesson, M., Johansson, P.-O., 1999. Stated preferences, real behaviour and anchoring: some empirical evidence. Environ. Resour. Econ. 13, $235-248$.

Payne, J.W., Schkade, D.A., Desvousges, W.H., Aultman, C., 2000. Valuation of multiple environmental programs. J. Risk Uncertain. 21 (1), 95-115.

Powe, N.A., Bateman, I.J., 2003. Ordering effects in nested 'top-down' and 'bottom-up' contingent valuation designs. Ecol. Econ. 45, $255-270$.

Protière, C., Donaldson, C., Luchini, S., Moatti, J.-P., Shackley, P., 2004. The impact of information on non-health attributes on willingness to pay for multiple health care programmes. Soc. Sci. Med. 58 (7), 1257-1269.

Selart, M., 1996. Structure compatibility and restructuring in judgment and choice. Organ. Behav. Hum. Perform. 65 (2), $106-116$.

Tversky, A., Kahneman, D., 1974. Judgement under uncertainty: heuristics and biases. Science 185, 1124-1131.

Van Exel, N.J.A., Brouwer, W.B.F., van den Berg, B., Koopmanschap, M.A., 2006. With a little help from an anchor. Discussion and evidence of anchoring effects in contingent valuation. J. Socio-Econ. 35, 836-853.

Veisten, K., Hoen, H., Starand, J., 2004. Sequencing and the adding-up property in contingent valuation of endangered species: are contingent non-use values economic values? Environ. Resour. Econ. 29, 419-433.

Wang, H., 1997. Contingent Valuation of Environmental Resources: a Stochastic Perspective. Ph.D. Dissertation. University of N. Carolina at Chapel Hill., School of Public Health.

Welch, B.L., 1947. The generalization of "Student's" problem when several different population variances are involved. Biometrika 34 (1-2), 28-35.

Welsh, M.P., Poe, G.L., 1998. Elicitation effects in contingent valuation: comparisons to a multiple bounded discrete choice approach. J. Environ. Econ. Manag. 36, 170-185.

Whitehead, J.C., 2002. Incentive incompatibility and starting-point bias in iterative valuation questions. Land Econ. 78, $285-297$.

Wilson, T., Houston, C., Etling, K., Brekke, N., 1996. A new look at anchoring effects: basic anchoring and its antecedents. J. Exp. Psychol. Gen. 125, 387-402.

Wooldridge, J.M., 2002. Econometric Analysis of Cross Section and Panel Data, second ed. MIT Press, Cambridge.

Yang, S.-H., Hu, W., Mupandawana, M., Liu, Y., 2012. Consumer willingness to pay for fair trade coffee: a Chinese case study. J. Agric. Appl. Econ. 44 (1), 21-34. 